\title{
Birth Planning in Uncertain or Life-Limiting Fetal Diagnoses: Perspectives of Physicians and Parents
}

\author{
DonnaMaria E. Cortezzo, MD, ${ }^{1-4}$ Katherine Bowers, $\mathrm{PhD}, \mathrm{MPH}^{5}$ and Marcella Cameron Meyer, $\mathrm{PhD}, \mathrm{MSW}^{6}$
}

\begin{abstract}
Background: Providers often use birth plans to document parents' wishes for their fetus with a life-limiting condition.

Objective: The objective of the study was to (1) discover important components of a birth plan for parents and providers who carry them out, and (2) understand the experience of parents and providers with birth plans.

Methods: The study design involves mixed-methods, descriptive, exploratory survey. This involves parents $(n=20)$ of a pregnancy complicated by a life-limiting diagnosis and providers who care for them $(n=116)$. The approach involves descriptive and univariate analyses for quantitative data and thematic analysis for qualitative data.

Results: Consistent components for families and physicians were diagnosis and medical management of the infant. Families gave greater emphasis on memory-making preferences. Parents feel birth plans give them a sense of control. Themes emerged from parents' experience of creating a birth plan are as follows: sense of control, therapeutic, memory making, effective communication, feeling prepared, and unexpected events. Most physicians feel comfortable discussing goals of care with families but report insufficient time. The importance of components of birth plans and perception of the parents' understanding of the prognosis varied by specialty. Discussion: Birth plans are beneficial and provide a greater sense of control for parents. Most physicians feel comfortable utilizing them. More than one-third of the physicians do not feel that they have time to complete a birth plan with parents. Communication between physicians and families about limitations of the plan and the potential trajectories could be improved. Communication between maternal and neonatal care providers regarding parent expectations and understanding could also be improved.
\end{abstract}

Keywords: birth plans; lethal prenatal diagnosis; neonate; perinatal palliative care

\section{Introduction}

D ESPITE ADVANCES IN THERAPIES, perinatal mortality rates have remained relatively constant. In the United States, there are $>1,000,000$ fetal deaths a year with $>20,000$ occurring after 20 weeks gestation. Over 15,000 neonatal deaths account for $\sim 70 \%$ of deaths within the first year of life. ${ }^{1}$ The 2012 perinatal mortality rate was 6.22 per 1000 live births. In 2013, over two-thirds of infant deaths occurred during the neonatal period with a neonatal mortality rate of 4.04 per 1000 live births. Most resulted from congenital malformations, deformations, and chromosomal anomalies diagnosed prenatally. ${ }^{2,3}$ Approximately one-third of deaths in U.S. children's hospitals occur in neonatal intensive care units. ${ }^{4}$ Consequently, most medical providers treating pregnant women or neonates will care for a pregnancy complicated by an uncertain, life-limiting, or lethal prognosis and help navigate goals of care. ${ }^{5}$

When families and physicians discuss pregnancies with life-limiting diagnoses, they consider medical interventions desired and how the family envisions spending time with their baby. Parents are experts regarding their beliefs, values,

\footnotetext{
${ }^{1}$ Department of Pediatrics, University of Cincinnati College of Medicine, Cincinnati, Ohio.

${ }^{2}$ Division of Neonatal and Pulmonary Biology, Cincinnati Children's Hospital Medical Center, Cincinnati, Ohio.

${ }^{3}$ Department of Anesthesiology, University of Cincinnati College of Medicine, Cincinnati, Ohio.

${ }_{5}^{4}$ Division of Pain and Palliative Medicine, Cincinnati Children's Hospital Medical Center, Cincinnati, Ohio.

${ }^{5}$ Division of Biostatistics and Epidemiology, Cincinnati Children's Hospital Medical Center, Cincinnati, Ohio.

${ }^{6}$ St. Elizabeth Hospice, St. Elizabeth Healthcare, Edgewood, Kentucky.

Accepted April 9, 2019.
} 
views of quality of life, and wishes regarding interventions. Parents who participate in family-centered care and medical decision making are more knowledgable about the diagnosis, disease trajectory, treatment options, and of implications of medical choices. ${ }^{6-8}$ Communication between all care teams and families is paramount to developing therapeutic alliances necessary to successfully navigate complex decisions. The principles of palliative care allow parents to express their wishes. 9,10

Birth plans are tools to facilitate informed choices for parents with a pregnancy complicated by a life-limiting diagnosis. ${ }^{5,11,12}$ Through shared decision making, they increase parental involvement and control. ${ }^{13}$ Often, perinatal palliative care teams develop birth plans with families, while obstetrical and neonatal health care providers carry them out. When this symbiotic relationship exists with multiple care teams, it is pertinent that teams developing plans understand the needs of families and those who will be carrying out plan details.

While many birth plan templates exist, it is unknown if they capture concerns of parents relaying wishes and physicians interpreting them to guide care. There is a need to improve communication between parents and health care providers by determining what parents wish to communicate and what providers wish to have clarified, so they can mutually and effectively attend to needs during pregnancy, delivery, and afterward.

This exploratory, mixed-methods study was designed to better understand experiences of parents and physicians with birth plans for pregnancies complicated by a life-limiting diagnosis. We also aimed to ascertain elements of birth plans important and helpful to parents and physicians who will be tasked with carrying them out. We hypothesized parents expecting a baby with a life-limiting diagnosis perceive benefit from, increased sense of control with, and improved communication with providers when utilizing a birth plan. We also hypothesized physicians feel more comfortable caring for these patients if they have a birth plan.

\section{Methods}

After Internal Review Board approval, parents and physicians (obstetricians [OBs], maternal-fetal medicine physicians [MFMs], pediatricians, and neonatologists) were surveyed regarding experiences with birth plans for pregnancies complicated by life-limiting diagnoses or uncertain prognosis and their perception of important birth plan components.

\section{Survey designs}

After a literature review, ${ }^{2,3,5-29}$ a web-based survey (Red$\mathrm{Cap}^{\circledR}$ ) was created and piloted through an iterative process.

Parent surveys consisted of demographics, pregnancy information, if they had a birth plan, important elements of birth plans, views about birth plans, and self-efficacy. Physician surveys consisted of demographics, beliefs regarding caring for pregnancies complicated by life-limiting fetal diagnoses, recent experiences with birth plans for affected pregnancies, and important elements of birth plans. A sevenpoint Likert scale was used. Participants could leave comments. The important elements of birth plans were based on the birth plan template used locally. Families could use this template, another template, or develop their own. Template is available upon request.

\section{Subjects}

Parent surveys were sent to all families enrolled in the institution's perinatal hospice and women seen at the institution's fetal care center with a diagnosis of severe congenital diaphragmatic hernia, Trisomy 13 or 18, renal agenesis, anencephaly, holoprosencephaly, severe skeletal dysplasia, limbbody wall complex, encephalocele, hypoplastic left heart syndrome, and potentially life-limiting anomalies, between January 1, 2015 and December 31, 2016, with an active e-mail address.

Physician surveys were sent to all Neonatal Care Association (NCA) members, a group of neonatologists, and pediatricians who cover delivery hospitals and all OBs and MFMs at hospitals NCA covers who had identifiable e-mails. Palliative care providers were not surveyed as, while they work closely with families on birth plans, they are not the providers initially responsible for carrying out the plans. In these centers, MFMs, OBs, pediatricians, and neonatologists are tasked with carrying out the family's wishes with input and support from the palliative care team.

\section{Data collection}

E-mail invitations were sent with a RedCap-generated survey link. Reminders of the close date were sent to physicians but not parents. RedCaps's ${ }^{\circledR}$ internal software organized responses. Data were deidentified and exported.

\section{Data analyses}

For qualitative analysis of comments, thematic analysis approach was utilized. For quantitative data, descriptive and univariate analyses were performed using $\mathrm{SAS}^{\circledR}$ version 9.4. Likert responses were considered as ordinal. Nonparametric tests were used to determine if responder type differed by responders' current views, current practices, or opinions regarding the utility and important elements of birth plans. To compare across physician specialties and between physicians and parents, a top box approach was used. To test for significance, the chi-squared test was used. A $p$-value $<0.05$ was considered statistically significant.

\section{Results}

Of 138 parents, 30 pediatricians, 43 neonatologists, 225 OBs, and 20 MFMs identified, response rates were as follows: 20/138 (14.5\%), 16/30 (53.3\%), 33/43 (76.7\%), 54/225 $(24.0 \%)$, and $13 / 20(65.0 \%)$, respectively.

The majority of physicians had over five years' experience and one to five patients with a pregnancy complicated by or a neonate with a life-limiting diagnosis in the past year (Table 1). Of the parents, the average maternal age was 31.1 years and most had college education. Twenty-five percent noted that this was their first pregnancy and $45.0 \%$ experienced a prior loss. The majority were diagnosed 20-30 weeks gestation and $80 \%$ resulted in live births (Table 2). Ninety percent had birth plans with three-quarters working on them with their obstetrician. One-third acknowledge working on birth plans with a perinatal hospice team. Most included diagnosis, desired mode of delivery, and desired medical management in them with variability around other elements (Table 3 ). 
Table 1. Characteristics of Physician Participants

\begin{tabular}{lc}
\hline & $N(\%)$ \\
\hline Sex & \\
Male & $47(40.6)$ \\
Specialty & \\
OB & $54(46.6)$ \\
Pediatrician & $16(13.8)$ \\
Maternal-fetal medicine & $13(11.2)$ \\
Neonatologist & $33(28.5)$ \\
Years of experience in profession & \\
$<5$ & $16(13.8)$ \\
$5-10$ & $26(22.4)$ \\
$11-15$ & $14(12.1)$ \\
$16-20$ & $15(12.9)$ \\
$21-25$ & $14(12.1)$ \\
$26-30$ & $8(6.9)$ \\
$>30$ & $23(19.8)$ \\
Approximate no. of patients with life-limiting condition in \\
the past year \\
0 & $12(10.3)$ \\
$1-5$ & $51(44.0)$ \\
$6-10$ & $17(14.7)$ \\
$11-15$ & $13(11.2)$ \\
$16-20$ & $1(0.9)$ \\
$>20$ & $21(18.1)$ \\
Unsure & $1(0.9)$ \\
\hline
\end{tabular}

OB, obstetrician.

When asked how important various elements were, there was variability. Nearly all felt wishes for medical management (including pain and symptom management) were important, most felt preferences for memory making were important, and over one-third did not feel end-of-life or autopsy preferences were important. See Table 4 for details. Interestingly, there was no difference in how parents and physicians ranked the importance of birth plan components other than more families stating that it was important to include testing completed or desired (data not shown). The vast majority of parents with birth plans felt that it was helpful and gave them a sense of control. The parents without birth plans stated one was never discussed. They did not feel that they had a sense of control. While they felt their wishes were heard, they stated that a birth plan would have been helpful and would have given them a sense of control.

Most physicians feel comfortable caring for these patients, addressing goals of care, and creating birth plans. They feel more comfortable knowing goals of care. However, over onethird do not feel they have time to complete birth plans with families, and there is variability around whether birth plans have all necessary information. See Table 5 for details. Comparing responses among specialties, there was a statistically significant difference in those who responded very strongly: they feel comfortable caring for these patients, feel comfortable addressing goals of care, feel families understand possible outcomes and how care paths alter the disease trajectory, key members have access to birth plans, and that birth plans have necessary information regarding the family's knowledge of the diagnosis/prognosis. See Table 6 for details.

Six themes emerged from parents' overall experience creating and using a birth plan: (1) sense of control, (2)
Table 2. Characteristics of Parent Participants

\begin{tabular}{|c|c|}
\hline & $\mathrm{N}(\%)$ \\
\hline Mother's age, years & $31.1\left(5.6^{\mathrm{a}}\right)$ \\
\hline Father's age, years & $32.9\left(5.8^{\mathrm{a}}\right)$ \\
\hline \multicolumn{2}{|l|}{ Mothers' education } \\
\hline Less than high school & $1(5.0)$ \\
\hline High school & $2(10.0)$ \\
\hline Some college/technical school & $4(20.0)$ \\
\hline Two-year degree & $2(10.0)$ \\
\hline Four-year degree & $8(40.0)$ \\
\hline Postgraduate & $3(15.0)$ \\
\hline \multicolumn{2}{|l|}{ Race/ethnicity } \\
\hline White non-Hispanic & $19(95.0)$ \\
\hline Black non-Hispanic & $1(5.0)$ \\
\hline \multicolumn{2}{|l|}{ Religion } \\
\hline Christian & $8(40.0)$ \\
\hline Catholic & $4(20.0)$ \\
\hline N/A/none/atheist & $8(40.0)$ \\
\hline First pregnancy & $5(25.0)$ \\
\hline Any prior pregnancy loss & $9(45.0)$ \\
\hline Miscarriage & $5(25.0)$ \\
\hline Stillbirth & $1(5.0)$ \\
\hline Type of loss not specified & $3(15.0)$ \\
\hline \multicolumn{2}{|l|}{ Diagnosis } \\
\hline Bladder outlet obstruction & $7(35.0)$ \\
\hline Genetic diagnosis/multiple anomalies & $2(10.0)$ \\
\hline Isolated CDH & $1(5.0)$ \\
\hline Isolated hypoplastic left heart syndrome & $1(5.0)$ \\
\hline Congenital pulmonary airway malformation & $2(10.0)$ \\
\hline Hypoplastic left heart syndrome and CDH & $2(10.0)$ \\
\hline Oral teratoma & $1(5.0)$ \\
\hline Other & $4(20.0)$ \\
\hline \multicolumn{2}{|l|}{ Gestational age diagnosis (weeks) } \\
\hline$<20$ & $8(40.0)$ \\
\hline $20-30$ & $12(60.0)$ \\
\hline Time of or after delivery & $2(10.0)$ \\
\hline Pregnancy resulted in a live birth & $16(80.0)$ \\
\hline The child is still alive & $4(25.0)$ \\
\hline
\end{tabular}

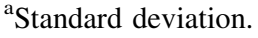

$\mathrm{CDH}$, congenital diaphragmatic hernia.

therapeutic, (3) memory making, (4) effective communication, (5) feeling prepared, and (6) unexpected events. See Table 7 for comments.

Four themes from physicians were as follows: (1) importance of birth plans, (2) need for meetings, (3) follow-through and communication, and (4) key components are needed with flexibility. See Table 7 for comments.

With uncertain prognoses, there was variability in details physicians find helpful. Many requested an algorithm with parental wishes for scenarios. "Maybe include a plan A, B, C if parents have not decided so that there is a clear path of what their choices are." They recommended including initial steps, "detailed enough to guide the team through initial resuscitation or comfort care. It should be clear...to both parties that further discussions will be needed as more information is available." Physicians desire "big picture values" and a summary of discussions: "Detail the options and possibilities that have been discussed prior." "[Stating] what we should do after delivery to try and clarify the diagnosis/ prognosis would be helpful.' They stressed limitations of 
Table 3. Participant's Birth Plans

\begin{tabular}{lr}
\hline & $\mathrm{N}(\%)$ \\
\hline Had a birth plan & $18(90.0)$ \\
Who they worked with on their birth plan & \\
OB & $13(72.2)$ \\
Perinatal hospice & $6(33.3)$ \\
Hospital perinatal coordinator & $3(16.6)$ \\
Specialist & $11(61.1)$ \\
Other & $2(11.1)$ \\
Elements included in their birth plan & \\
Baby's diagnosis & $18(100.0)$ \\
Tests during pregnancy & $13(72.2)$ \\
Mode of delivery & $17(94.4)$ \\
Preference for fetal monitoring & $12(66.7)$ \\
Who to call & $9(50.0)$ \\
Who to be present in delivery room & $12(66.7)$ \\
Comfort care, CPR & $13(72.2)$ \\
Wishes for memory making & $5(27.8)$ \\
Wishes for religious ritual & $7(38.9)$ \\
Funeral/end-of-life instructions & $4(22.2)$ \\
Autopsy preference & $5(27.8)$ \\
Other & $1(5.6)$ \\
Staff was aware of their birth plan & $14(77.8)$ \\
\hline
\end{tabular}

${ }^{\mathrm{a}}$ Can select more than one. plans and importance of discussions after birth with comments such as "understanding that the baby's condition may require deviation from the birth plan," and it is "preferable to have ongoing conversations with the family... as more information is known."

\section{Discussion}

The importance of and challenges in providing quality neonatal-perinatal palliative care as a collaborative process between parents and physicians have been acknowledged for $>40$ years. $^{30-34}$ Providers utilize perinatal palliative care to support individuals whose pregnancy is complicated with a fetal diagnosis forecasting an uncertain or life-limiting prognosis. $5,11,12,14,21,27,35-40$ Often, as in this study, families develop plans with perinatal palliative care teams, while maternal and neonatal health care providers initiate those plans. They rely on the expertise and skills of palliative care teams to convey goals of care and desired plans for delivery and afterward. If a palliative care team is not available or not involved, maternal and neonatal physicians must have these conversations and develop thoughtful plans with families.

Several studies highlight the importance of building strong therapeutic relationships with families as quality indicators of parental satisfaction with perinatal palliative care and their experiences with care teams throughout pregnancy and

Table 4. Parental Opinions Regarding Birth Plans

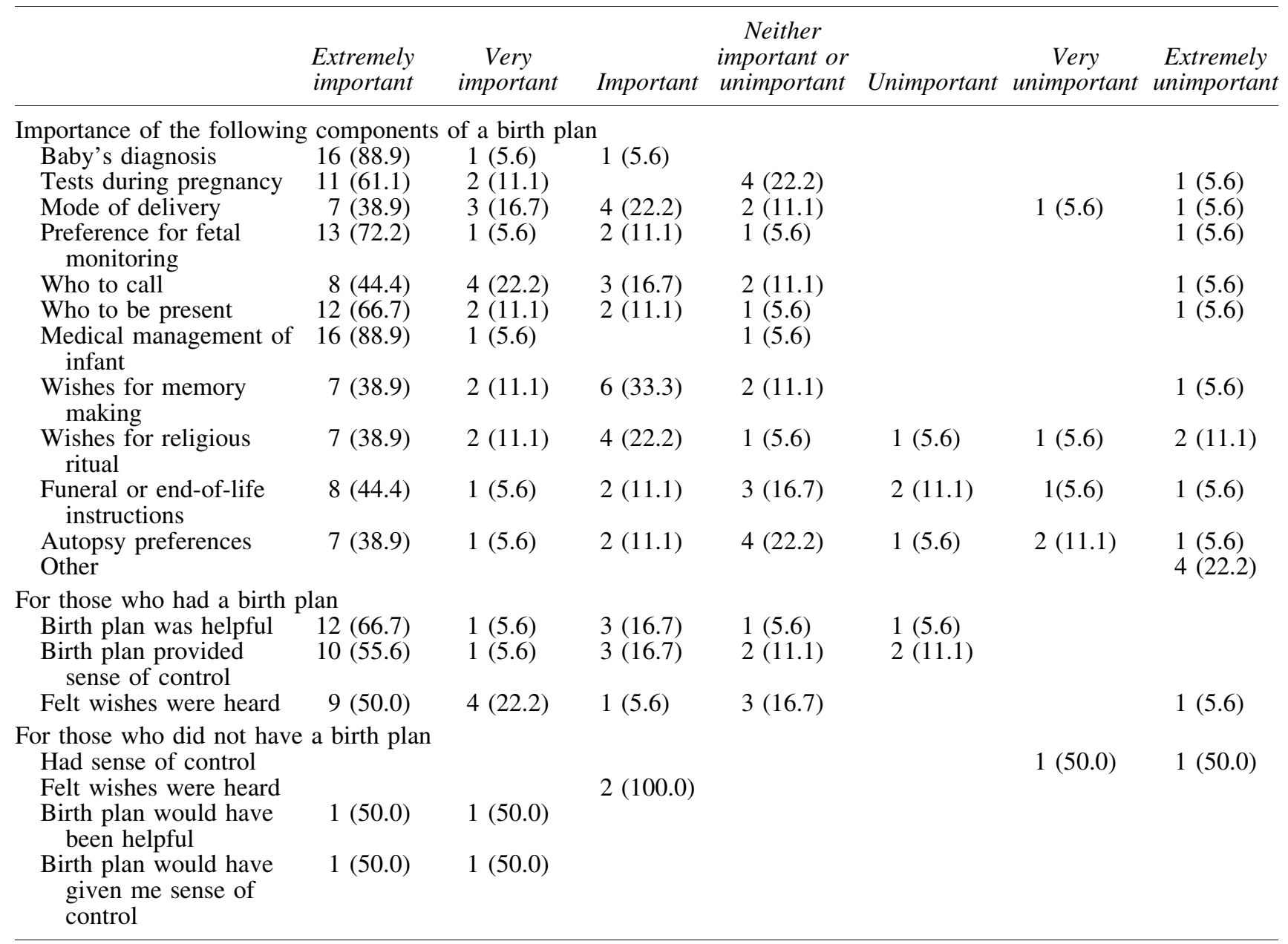


Table 5. Physician Beliefs and Opinions

\begin{tabular}{|c|c|c|c|c|c|c|c|}
\hline & $\begin{array}{l}\text { Very } \\
\text { strongly } \\
\text { agree }\end{array}$ & $\begin{array}{l}\text { Strongly } \\
\text { agree }\end{array}$ & Agree & $\begin{array}{l}\text { Neither agree } \\
\text { or disagree }\end{array}$ & Disagree & $\begin{array}{l}\text { Strongly } \\
\text { disagree }\end{array}$ & $\begin{array}{l}\text { Very } \\
\text { strongly } \\
\text { disagree }\end{array}$ \\
\hline \multicolumn{8}{|c|}{ Personal beliefs and opinions about providing care, $N=116$} \\
\hline $\begin{array}{l}\text { I feel comfortable caring for } \\
\text { these patients }\end{array}$ & $31(26.7)$ & $46(39.7)$ & $29(25.0)$ & $1(0.9)$ & $5(4.3)$ & $4(3.5)$ & \\
\hline $\begin{array}{l}\text { I feel comfortable addressing } \\
\text { goals of care }\end{array}$ & $29(25.0)$ & $40(34.5)$ & $38(32.8)$ & $2(1.7)$ & $4(3.5)$ & $2(1.7)$ & $1(0.9)$ \\
\hline $\begin{array}{l}\text { I feel comfortable creating a } \\
\text { birth plan with family }\end{array}$ & $23(19.8)$ & $29(25.0)$ & $37(31.9)$ & $8(6.9)$ & $13(11.2)$ & $3(2.6)$ & $3(2.6)$ \\
\hline $\begin{array}{l}\text { I have time to complete birth } \\
\text { plan with family }\end{array}$ & $7(6.0)$ & $12(10.3)$ & $29(25.0)$ & $23(19.8)$ & $34(29.3)$ & $7(6.0)$ & $4(3.5)$ \\
\hline $\begin{array}{l}\text { I feel more comfortable when } \\
\text { there is a birth plan }\end{array}$ & $37(31.9)$ & $36(31.0)$ & $27(32.3)$ & $13(11.2)$ & $3(2.6)$ & & \\
\hline $\begin{array}{l}\text { I feel more comfortable } \\
\text { knowing family's goals of } \\
\text { care }\end{array}$ & $60(51.7)$ & $40(34.5)$ & $16(13.8)$ & & & & \\
\hline $\begin{array}{l}\text { More can be done to ensure } \\
\text { care team aware of goals }\end{array}$ & $34(29.3)$ & 37 (31.9) & $32(27.6)$ & $11(9.5)$ & $2(1.7)$ & & \\
\hline $\begin{array}{l}\text { Parents should make decision } \\
\text { about goals of care }\end{array}$ & $30(25.9)$ & $31(26.7)$ & $38(32.8)$ & $13(11.2)$ & $4(3.5)$ & & \\
\hline $\begin{array}{l}\text { The care team should make } \\
\text { decision about care based } \\
\text { on values of family }\end{array}$ & $18(15.5)$ & $25(21.6)$ & $31(26.7)$ & $23(19.8)$ & $17(14.7)$ & $1(0.9)$ & $1(0.9)$ \\
\hline $\begin{array}{l}\text { Goals should be a joint } \\
\text { decision process }\end{array}$ & $54(46.6)$ & $31(26.7)$ & $26(22.3)$ & $4(3.5)$ & $1(0.9)$ & & \\
\hline Birth plans empower families & $38(32.8)$ & $35(30.2)$ & $31(26.7)$ & $11(9.5)$ & $1(0.9)$ & & \\
\hline $\begin{array}{l}\text { Families tend to understand } \\
\text { outcomes and care paths }\end{array}$ & $7(6.0)$ & $13(11.2)$ & $41(35.3)$ & $12(10.3)$ & $39(33.6)$ & $3(2.6)$ & $1(0.9)$ \\
\hline \multicolumn{8}{|c|}{ Beliefs and opinions about birth plans for these patients, $N=103$} \\
\hline Birth plans are helpful & $20(19.4)$ & $32(31.1)$ & $42(40.8)$ & $9(7.8)$ & $1(1.0)$ & & \\
\hline $\begin{array}{l}\text { Key members of care team } \\
\text { have access to birth plans }\end{array}$ & $16(15.5)$ & $22(21.4)$ & $32(31.1)$ & $15(15.6)$ & $16(15.5)$ & $2(1.9)$ & \\
\hline $\begin{array}{l}\text { Direct communication with } \\
\text { providers working with } \\
\text { families on birth plan is } \\
\text { beneficial }\end{array}$ & $35(34.3)$ & $40(39.2)$ & $23(22.6)$ & $3(2.9)$ & $1(1.0)$ & & \\
\hline \multicolumn{8}{|c|}{ Birth plans have all necessary info for care team regarding } \\
\hline $\begin{array}{l}\text { Family knowledge of the } \\
\text { diagnosis }\end{array}$ & $8(7.8)$ & $23(22.6)$ & $30(29.4)$ & $22(21.6)$ & $17(16.7)$ & $2(2.0)$ & \\
\hline $\begin{array}{l}\text { Labor and delivery } \\
\text { preferences }\end{array}$ & $11(10.7)$ & $20(19.4)$ & $32(31.1)$ & $24(23.3)$ & $14(13.6)$ & $2(1.9)$ & \\
\hline $\begin{array}{l}\text { Desired interventions at } \\
\text { delivery }\end{array}$ & $13(12.6)$ & $24(23.3)$ & $26(25.2)$ & $26(25.2)$ & $12(11.7)$ & $2(1.9)$ & \\
\hline $\begin{array}{l}\text { Desired interventions in the } \\
\text { neonatal course }\end{array}$ & $12(11.7)$ & $22(21.4)$ & $29(28.2)$ & $24(23.3)$ & $15(14.6)$ & $1(1.0)$ & \\
\hline $\begin{array}{l}\text { Goals of care when the } \\
\text { prognosis is uncertain }\end{array}$ & $12(11.7)$ & $15(14.6)$ & $27(26.2)$ & $28(27.2)$ & $16(15.5)$ & $4(3.9)$ & $1(1.0)$ \\
\hline $\begin{array}{l}\text { Plan if the baby survives to } \\
\text { discharge }\end{array}$ & $10(9.7)$ & $14(13.6)$ & $22(21.4)$ & $32(31.1)$ & $20(19.4)$ & $4(3.9)$ & $1(1.0)$ \\
\hline $\begin{array}{l}\text { If the baby dies before } \\
\text { discharge }\end{array}$ & $11(10.7)$ & $16(15.5)$ & $28(27.2)$ & $31(30.1)$ & $14(13.6)$ & $3(2.9)$ & \\
\hline $\begin{array}{l}\text { Testing and subspecialties } \\
\text { that should be contacted }\end{array}$ & $10(9.8)$ & $18(17.7)$ & $24(23.5)$ & $27(26.5)$ & $20(19.6)$ & $2(2.0)$ & $1(1.0)$ \\
\hline Memory making & $8(7.8)$ & $15(14.7)$ & $29(28.4)$ & $34(33.3)$ & $13(12.8)$ & $3(2.9)$ & \\
\hline Support for the family & $8(7.8)$ & $17(16.7)$ & $29(28.4)$ & $29(28.4)$ & $15(14.7)$ & $4(3.9)$ & \\
\hline
\end{tabular}

afterward. ${ }^{14,18,25,40-42}$ Communication between parents and all health care providers is pertinent, so parents feel involved, have a parental role, and have their wishes respected. ${ }^{9,10}$ Parents who share in medical decision making are more knowledgable and clear about their wishes, demonstrating principles of family-centered care. , $7,11,12^{-12}$
Despite recent acknowledgment of the importance of neonatal-perinatal palliative care, there is a shortage of studies describing what is important to parents and physicians in planning during a pregnancy complicated by a fetus with a potentially life-limiting diagnosis. This study of parents and physicians describes views of birth plans and pertinent 
Table 6. Comparison of Physician Specialties Responding Strongly or Very Strongly Agree

\begin{tabular}{|c|c|c|c|c|c|}
\hline Variables & $O B 54$ & Pediatrician 16 & MFM 13 & Neonatologist 33 & $\mathrm{p}$ \\
\hline I feel comfortable caring for these patients & $13(24.1)$ & $1(6.3)$ & $9(69.2)$ & $8(24.2)$ & 0.0001 \\
\hline I feel comfortable addressing goals of care & $12(22.2)$ & $1(6.3)$ & $9(69.2)$ & $7(21.2)$ & 0.0007 \\
\hline I feel comfortable creating a birth plan with family & $11(20.4)$ & $1(6.3)$ & $4(30.8)$ & $7(21.2)$ & 0.41 \\
\hline I have time to complete birth plan with family & $11(20.4)$ & $0(0)$ & $2(15.4)$ & $6(18.2)$ & 0.28 \\
\hline I feel more comfortable when there is a birth plan & $20(37.0)$ & $2(12.5)$ & $5(38.5)$ & $10(30.3)$ & 0.29 \\
\hline I feel more comfortable knowing family's goals of care & $31(57.4)$ & $4(25.0)$ & $9(69.2)$ & $16(48.5)$ & 0.07 \\
\hline More can be done to ensure care team aware of goals & $15(27.8)$ & $5(31.3)$ & $3(23.1)$ & $11(33.3)$ & 0.90 \\
\hline Parents should make decision about goals of care & $17(31.5)$ & $1(6.3)$ & $3(23.1)$ & $9(27.3)$ & 0.24 \\
\hline $\begin{array}{l}\text { The care team should make decision about care based } \\
\text { on values of family }\end{array}$ & $9(16.7)$ & $1(6.3)$ & $2(15.4)$ & $6(18.2)$ & 0.73 \\
\hline Goals should be a joint decision process & $23(42.6)$ & $5(31.3)$ & $6(46.2)$ & $20(60.6)$ & 0.22 \\
\hline Birth plans empower families & $20(37.0)$ & $1(6.3)$ & $4(30.8)$ & $13(39.4)$ & 0.10 \\
\hline Families tend to understand outcomes and care paths & $16(29.6)$ & $0(0)$ & $2(15.4)$ & $2(6.1)$ & 0.007 \\
\hline Birth plans are helpful & $7(13.0)$ & $1(6.3)$ & $4(30.8)$ & $8(24.2)$ & 0.18 \\
\hline Key members of care team have access to birth plans & $8(14.8)$ & $0(0)$ & $6(46.2)$ & $2(6.1)$ & 0.001 \\
\hline $\begin{array}{l}\text { Direct communication with providers working with } \\
\text { families on birth plan is beneficial }\end{array}$ & $15(27.8)$ & $1(6.3)$ & $5(38.5)$ & $14(42.4)$ & 0.06 \\
\hline \multicolumn{6}{|l|}{ Birth plans have all necessary info for care team regarding } \\
\hline Family knowledge of diagnosis & $18(33.3)$ & $2(12.5)$ & $6(46.2)$ & $5(15.2)$ & 0.05 \\
\hline Labor and delivery preferences & $7(13.0)$ & $1(6.3)$ & $2(15.4)$ & $1(3.0)$ & 0.38 \\
\hline Desired interventions at delivery & $8(14.8)$ & $1(6.3)$ & $3(23.1)$ & $1(3.0)$ & 0.16 \\
\hline Desired interventions in the neonatal course & $8(14.8)$ & $1(6.3)$ & $3(23.1)$ & $0(0)$ & 0.06 \\
\hline Goals of care when the prognosis is uncertain & $8(14.8)$ & $1(6.3)$ & $3(23.1)$ & $0(0)$ & 0.06 \\
\hline Plan if the baby survives to discharge & $16(29.6)$ & $1(6.3)$ & $3(23.1)$ & $4(12.1)$ & 0.10 \\
\hline If the baby dies before discharge & $7(13.0)$ & $1(6.3)$ & $3(23.1)$ & $0(0)$ & 0.07 \\
\hline Testing and subspecialties that should be contacted & $7(13.0)$ & $1(6.3)$ & $2(15.4)$ & $0(0)$ & 0.15 \\
\hline Memory making & $13(24.1)$ & $1(6.3)$ & $5(38.5)$ & $4(12.1)$ & 0.09 \\
\hline Support for the family & $14(25.9)$ & $1(6.3)$ & $5(38.5)$ & $5(15.2)$ & 0.12 \\
\hline
\end{tabular}

MFM, maternal-fetal medicine physician.

components to facilitate positive experiences for families and providers. By recognizing the aspects important to parents and physicians who are responsible for carrying out plans developed prenatally, perinatal palliative care providers can tailor plans and conversations to more consistently meet needs of family members and care providers. It highlights the importance of communication between physicians developing birth plans with families and other care team members.

Birth plans aid in shared decision making between staff and parents, increasing parental sense of mastery and control by allowing them to be primary caretakers and decision makers in difficult situations. ${ }^{13}$ The medical team needs to support families and help navigate through decisions. There remains a need for provider education, so birth plans are utilized. $^{23}$ This study shows that, while most physicians feel comfortable engaging in conversations with families, most do not have time to complete birth plans. Perinatal palliative care teams, with specialized training, often develop birth plans with families; it is important they communicate the plan to physicians caring for the mother and neonate.

Parents and physicians agree on the importance of birth plans and recognize them as a "process" rather than a

Table 7. Sample Comments from Parents and Physicians

Comments from parents

Parent 1:"I felt like I was able to parent my daughter and advocate for her."

Parent 2: "The process was traumatic and anxiety inducing but also cathartic."

Parent 3: "I... had preferences for memory making, funeral plans, etc."

Parent 4: "The entire team was on the same page"; and "everyone worked well together."

Parent 5: "It was good to know what to expect"; and "we liked knowing what was going to happen."

Parent 6: "was not anticipating being in the moment of my child's death and wanting to do everything to save her even though I knew she was suffering...emotions for your sick child suffering in your arms is unbearable."

Comments from physicians

Physician 1: "assisting in coordination and care in these very delicate and difficult situations."

Physician 2: "A little bit of lead time is always helpful...to acquaint myself with the needs and wishes of the family, and preferably to speak with them in person before the delivery."

Physician 3: "Birth plans should be started throughout prenatal care, updated at each prenatal visit... not at one sitting."

Physician 4: "Negative reactions that come from individuals being uncomfortable with what is being requested, and not having been part of the development of the birth plan."

Physician 5: "I feel it is better to delineate the major points and allow for some variation as the situation plays out." 
document. The partnership that ensues from exchanging information and values improves experiences. Parents note the therapeutic value of preparing a plan, which acknowledges their parental role in a situation where they have little control. Physicians emphasize the need for multiple meetings. The communication of parents' wishes, collaboration, and followup afterward is important and necessary. Birth plans are most effective when practitioners are skilled in utilizing them.

When a family learns of a life-limiting condition prenatally, they begin grieving the loss of a healthy pregnancy and may need help in reframing hope. The health care team has a unique opportunity to support the family and help them find meaning in their baby's life. The team can facilitate bonding and memory making throughout pregnancy and afterward. They can navigate goals of care and develop a birth plan known by all providers. ${ }^{5}$

Maternal and neonatal providers often appreciate involvement of a palliative care team to clarify goals and discuss intricate medical plans. ${ }^{37,40,43,44}$ So that parents feel heard and providers feel comfortable, a delivery room resuscitation plan should be discussed and documented. ${ }^{37,38,40,43,44}$ This, along with the importance of flexibility and discussing all potential outcomes, was emphasized in our study. Parents, as supported by this study, wish to be included and feel empowered when they are involved in decision making. ${ }^{45-52}$

The perinatal/neonatal period is usually a time of joy, anticipation of life by a growing family. When a life-limiting diagnosis is made, the remainder of the pregnancy and time afterward are vastly different than what was anticipated and hoped for. ${ }^{26,35,37,39,53-55}$ Our results suggest sharing in decisions and indicating preferences for memory making allow parents to care and advocate for their baby. This contributes to parent-child bonding and attachment. ${ }^{56}$

To provide quality neonatal-perinatal palliative care, a better understanding of perspectives, current practices, and important components of birth plans is needed. This study shows that MFMs feel comfortable caring for this patient population and addressing goals of care more often than other providers. While pediatricians will likely interact with these families, especially if they wish for comfort measures only approach to care, they rarely feel comfortable caring for them. This may be because MFMs have the opportunity to meet the family multiple times, and develop a therapeutic relationship with the family and other providers. They are likely having conversations with neonatologists and palliative care providers over a course of months as opposed to a pediatrician who may not meet the family or palliative care team until after delivery. They may not have been aware of the upcoming delivery or details of the birth plan. It is also possible that MFMs and neonatologists have additional training around communication and principles of palliative care, and work closely with palliative care teams.

Interestingly, OBs and MFMs are more likely to feel that team members are aware of birth plans, and families have a clear understanding of the diagnosis and impact of different care paths on disease trajectory than pediatricians or neonatologists. They also feel birth plans convey the family's knowledge about the diagnosis and prognosis more so than pediatricians and neonatologists do. These perceived differences between those caring for the mother before delivery and the neonate afterward suggest that there is a need for improved communication and shared understanding among team members. A perinatal palliative care team may bridge this gap, so there is a consistent presence during transitions of care. There are also opportunities to improve communications by having systems in place to discuss among palliative care providers, MFMs/OBs, and neonatologists/ pediatricians upcoming deliveries. This would allow a format for questions and concerns to be addressed. With electronic medical records, once birth plans are completed, they can be attached to the principal diagnosis or in the advance care plan section. There can also be a shared list in the electronic medical record among all appropriate care providers of upcoming deliveries.

As a descriptive study, it is limited by accuracy of selfreporting. Also, patients and providers without e-mail were not represented. The effective response rate, although not atypical, raises additional concern of generalizability. The low response rate may be due to high number of survey requests, survey length, and lack of compensation. It is possible that those who responded have a special interest in, strong beliefs about, or experiences with birth plans, thus conveying a response bias. Their views or experiences may not be reflective of other families or physicians.

\section{Conclusion}

Despite the regular occurrence of a pregnancy complicated by a potentially life-limiting diagnosis, care provided and discussions afterward are variable. This study suggests that families derive benefit and a sense of control from birth plans. There is variability among families and physicians who carry out birth plans about what components are important to include. Most agree that diagnosis and wishes for maternal and neonatal medical care are important. Families placed greater emphasis on memory making and how to spend time with their baby.

Practitioners want initial management steps and what needs to be learned for the family to make decisions consistent with their values and wishes for their baby. What maternal care providers perceive as the family's understanding during pregnancy is discrepant from what neonatal providers perceive after the neonate is born. As parents recognize some unexpected occurrences or unanticipated decisions, physicians request greater emphasis be placed on limitations of the plan and what can be known before birth.

This study supports the need to further explore what families wish to convey to providers, and communication between maternal and neonatal care providers when there is a pregnancy complicated by a potentially life-limiting illness. It is important that palliative care providers recognize needs of both the family and the physician who will carry out the plans. Future studies can expand on this to help develop a comprehensive and effective birth plan template. The results also highlight that birth plans, while important, are tools to foster communication. There is opportunity to investigate and improve systems to foster communications between palliative care providers, maternal physicians, and neonatal physicians.

\section{Author Disclosure Statement}

No competing financial interests exist. 


\section{References}

1. MacDorman MF, Gregory EC: Fetal and perinatal mortality: United States, 2013. Natl Vital Stat Rep 2015;64:1-24.

2. Osterman MJ, Martin JA, Curtin SC, et al.: Newly released data from the revised U.S. birth certificate, 2011. Natl Vital Stat Rep 2013;62:1-22.

3. Lorenz JM, Ananth CV, Polin RA, D'Alton ME: Infant mortality in the United States. J Perinatol 2016;36:797801.

4. Brandon D, Docherty SL, Thorpe J: Infant and child deaths in acute care settings: Implications for palliative care. J Palliat Med 2007;10:910-918.

5. Cortezzo DE, Carter B: Palliative Care. Avery's Disease of the Newborn. Philadelphia, PA: Elsevier, 2018, pp. 446-452.

6. Barry MJ, Edgman-Levitan S: Shared decision makingPinnacle of patient-centered care. N Engl J Med 2012;366: 780-781.

7. Brinkman WB, Hartl Majcher J, Poling LM, et al.: Shared decision-making to improve attention-deficit hyperactivity disorder care. Patient Educ Couns 2013;93:95-101.

8. Haug S, Goldstein M, Cummins D, et al.: Using patientcentered care after a prenatal diagnosis of Trisomy 18 or Trisomy 13: A review. JAMA Pediatr 2017;171:382-387.

9. Cortezzo DE, Sanders MR, Brownell EA, Moss K: End-oflife care in the neonatal intensive care unit: Experiences of staff and parents. Am J Perinatol 2015;32:713-724.

10. Hughes K, Goodall U: Perinatal bereavement care: Are we meeting families' needs? Br J Midwif 2013;21:248-253.

11. Leong Marc-Aurele K, Nelesen R: A five-year review of referrals for perinatal palliative care. J Palliat Med 2013;16: 1232-1236.

12. McNamara K, O’Donoghue K, O'Connell O, Greene R: Antenatal and intrapartum care of pregnancy complicated by lethal fetal anomaly. Obstetrician Gynaecologist 2013; 15:189-194.

13. Whitford HM, Entwistle VA, van Teijlingen E, et al.: Use of a birth plan within woman-held maternity records: A qualitative study with women and staff in northeast Scotland. Birth 2014;41:283-289.

14. Bakhbakhi D, Siassakos D, Storey C, et al.: PARENTS 2 study protocol: Pilot of Parents' Active Role and ENgagement in the review of Their Stillbirth/perinatal death. BMJ Open 2018;8:e020164.

15. Beck AM, Konnert CA: Ethical issues in the study of bereavement: The opinions of bereaved adults. Death Stud 2007;31:783-799.

16. Cortezzo DE, Sanders MR, Brownell E, Moss K: Neonatologists' perspectives of palliative and end-of-life care in neonatal intensive care units. J Perinatol 2013;33:731-735

17. Dyregrov K: Bereaved parents' experience of research participation. Soc Sci Med 2004;58:391-400.

18. Flenady V, Boyle F, Koopmans L, et al.: Meeting the needs of parents after a stillbirth or neonatal death. BJOG 2014; 121 Suppl 4:137-140.

19. Garten L, von der Hude K, Rösner B, et al.: [Individual neonatal end-of-life care and family-centred bereavement support]. Z Geburtshilfe Neonatol 2013;217:95-102.

20. Davies B, Sehring SA, Partridge JC, et al.: Barriers to palliative care for children: Perceptions of pediatric health care providers. Pediatrics 2008;121:282-288.

21. Lathrop A, Vandevusse L: Affirming motherhood: Validation and invalidation in women's perinatal hospice narratives. Birth 2011;38:256-265.
22. Marc-Aurele KL, Hull AD, Jones MC, Pretorius DH: A fetal diagnostic center's referral rate for perinatal palliative care. Ann Palliat Med 2018;7:177-185.

23. Penny Simkin P: Birth plans: After 25 years, women still want to be heard. Birth 2007;34:49-51.

24. Snaman JM, Kaye EC, Levine DR, et al.: Empowering bereaved parents through the development of a Comprehensive Bereavement Program. J Pain Symptom Manage 2017;53:767-775.

25. Wool C: Instrument psychometrics: Parental satisfaction and quality indicators of perinatal palliative care. J Palliat Med 2015;18:872-877.

26. Catlin A, Brandon D, Wool C, Mendes J: Palliative and end-of-life care for newborns and infants: From the National Association of Neonatal Nurses. Adv Neonatal Care 2015; 15:239-240.

27. Wilke J, Limbo R: Resolve Through Sharing Bereavement Training in Perinatal Death, 8 ed. La Crosse, WI: Gundersen Lutheran Medical Foundation, Inc., 2012.

28. Charmaz K: Grounded theory in the 21st century: Applications for advancing social justice studies. In: Denzin K, Lincoln YS (ed): The Sage Handbook of Qualitative Research. Thousand Oaks, CA: Sage Publications, 2004, pp. 501-535.

29. Corbin J, Strauss A: Basics of Qualitative Research, 3rd ed. Los Angeles, CA: Sage Publications, 2008.

30. Duff RS, Campbell AG: Moral and ethical dilemmas in the special-care nursery. N Engl J Med 1973;289:890894.

31. Whitfield JM, Siegel RE, Glicken AD, et al.: The application of hospice concepts to neonatal care. Am J Dis Child 1982;136:421-424.

32. Landon-Malone KA, Kirkpatrick JM, Stull SP: Incorporating hospice care in a community hospital NICU. Neonatal Netw 1987;6:13-19.

33. Butler NC: The NICU culture versus the hospice culture: can they mix? Neonatal Netw 1986;5:35-42.

34. Silverman WA: A hospice setting for humane neonatal death. Pediatrics 1982;69:239.

35. Carter BS: Providing palliative care for newborns. Pediatr Ann 2004;33:770-777.

36. Kobler K, Limbo R: Making a case: Creating a perinatal palliative care service using a perinatal bereavement program model. J Perinat Neonatal Nurs 2011;25:32-41; quiz 2-3.

37. Balaguer A, Martín-Ancel A, Ortigoza-Escobar D, et al.: The model of palliative care in the perinatal setting: A review of the literature. BMC Pediatr 2012;12:25.

38. Engelder S, Davies K, Zeilinger T, Rutledge D: A model program for perinatal palliative services. Adv Neonatal Care 2012;12:28-36.

39. Breeze AC, Lees CC, Kumar A, et al.: Palliative care for prenatally diagnosed lethal fetal abnormality. Arch Dis Child Fetal Neonatal Ed 2007;92:F56-F58.

40. Widger K, Picot C: Parents' perceptions of the quality of pediatric and perinatal end-of-life care. Pediatr Nurs 2008; 34:53-58.

41. Gold KJ: Navigating care after a baby dies: A systematic review of parent experiences with health providers. J Perinatol 2007;27:230-237.

42. Guon J, Wilfond BS, Farlow B, et al.: Our children are not a diagnosis: The experience of parents who continue their pregnancy after a prenatal diagnosis of Trisomy 13 or 18 . Am J Med Genet A 2014;164A:308-318. 
43. Kenner C, Press J, Ryan D: Recommendations for palliative and bereavement care in the NICU: A family-centered integrative approach. J Perinatol 2015;35 Suppl 1:S19-S23.

44. Catlin A, Carter B: Creation of a neonatal end-of-life palliative care protocol. J Perinatol 2002;22:184-195.

45. Armentrout D, Cates LA: Informing parents about the actual or impending death of their infant in a newborn intensive care unit. J Perinat Neonatal Nurs 2011;25:261-267.

46. Berg S: In their own voices: Families discuss end-of-life decision making-Part 2. Pediatr Nurs 2006;32:238-242, 237.

47. Brosig CL, Pierucci RL, Kupst MJ, Leuthner SR: Infant end-of-life care: The parents' perspective. J Perinatol 2007; 27:510-516.

48. Contro N, Larson J, Scofield S, et al.: Family perspectives on the quality of pediatric palliative care. Arch Pediatr Adolesc Med 2002;156:14-19.

49. Davies B, Connaughty S: Pediatric end-of-life care: Lessons learned from parents. J Nurs Adm 2002;32:5-6.

50. Dokken DL: In their own voices: Families discuss end-oflife decision making-Part 1. Interview by Elizabeth Ahmann. Pediatr Nurs 2006;32:173-175.

51. Eden LM, Callister LC: Parent involvement in end-of-life care and decision making in the Newborn Intensive Care Unit: An integrative review. J Perinat Educ 2010;19:29-39.
52. Henley A, Schott J: The death of a baby before, during or shortly after birth: Good practice from the parents' perspective. Semin Fetal Neonatal Med 2008;13:325328.

53. Carter BS, Hubble C, Weise KL: Palliative medicine in neonatal and pediatric intensive care. Child Adolesc Psychiatr Clin N Am 2006;15:759-777.

54. Romesberg TL: Building a case for neonatal palliative care. Neonatal Netw 2007;26:111-115.

55. Munson D, Leuthner SR: Palliative care for the family carrying a fetus with a life-limiting diagnosis. Pediatr Clin North Am 2007;54:787-798, xii.

56. Klaus M, Kennell J, Klaus P: Bonding: Building the Foundations of Secure Attachment and Independence: Da Capo Lifelong Books, Boston, MA, 1996.

Address correspondence to: Marcella Cameron Meyer, PhD, MSW St. Elizabeth Hospice St. Elizabeth Healthcare 483 South Loop Road Edgewood, $K Y 41017$

E-mail: marcella.cameronmeyer@stelizabeth.com 